Published in "Journal of Vertebrate Paleontology 35(2): e909450, 2015"

which should be cited to refer to this work.

\title{
THE FIRST SOFT-SHELLED TURTLE FROM THE JEHOL BIOTA OF CHINA
}

\author{
LU LI, ${ }^{1,2}$ WALTER G. JOYCE, ${ }^{3, *}$ and JUN LIU ${ }^{1}$ \\ ${ }^{1}$ Key Laboratory of Vertebrate Evolution and Human Origins, Institute of Vertebrate Paleontology and Paleoanthropology, \\ Chinese Academy of Sciences, Beijing 100044, China, lilu0ivpp@gmail.com; liujun@ivpp.ac.cn; \\ ${ }^{2}$ University of Chinese Academy of Science, Beijing 100049, China; \\ ${ }^{3}$ Department of Geosciences, University of Fribourg, 1700 Fribourg, Switzerland, walter.g.joyce@gmail.com
}

\begin{abstract}
A new turtle from the Early Cretaceous (Aptian) Jiufotang Formation of western Liaoning, China, Perochelys lamadongensis, gen. et sp. nov., represents the first species of soft-shelled turtle from the Jehol Biota. The new taxon is diagnosed by the combination of the following characters: nuchal bone about five times wider than long; preneural absent; reversal of the orientation in the neural series at neural V; neural series fully separates costal series; costal VIIIs reduced; plastral callosities poorly developed and poorly sculpted; postorbital bar narrow, around one-fourth of orbit diameter; jugal contacting squamosal; foramen jugulare posterius separated from fenestra postotica; neural spines weakly developed on anterior cervicals; and phalangeal formula for pes 2-3-3-4-?. High levels of homoplasy make the phylogenetic relationships of the new taxon difficult to assess, and the possibility therefore exists that Perochelys lamadongensis either represents a stem or a crown trionychid. This phylogenetic uncertainty confirms that the skeletal morphology of trionychids has remained virtually unchanged for the last 120 million years.
\end{abstract}

http://zoobank.org/urn:lsid:zoobank.org:pub:1FE50A16-5FE6-4DEE-B839-CE2A52038F55

\section{INTRODUCTION}

The Early Cretaceous (Aptian) Jehol Biota of China is famous for its great variety of exceptionally preserved fossils that provide important insights into a wide range of evolutionary, paleoecological, and phylogenetic questions (Chang et al., 2003; Zhou et al., 2003). Turtles were one of the earliest reported vertebrates from the Jehol Biota (Endo and Shikama, 1942; Zhou, 2010a), but the group has attracted significantly less attention relative to many other groups, although many well-preserved specimens are housed in public institutions. The first named turtle from the Jehol biota is Manchurochelys manchoukuoensis (Endo and Shikama, 1942; Zhou, 2010a). The second species, Manchurochelys liaoxiensis, was not named until 1995 (Ji, 1995). This species was soon after restudied and transferred to the genus Ordosemys $(\mathrm{Li}$ and Liu, 1999; Tong et al., 2004). Recently, a third species, Liaochelys jianchangensis, was reported from the Jiufotang Formation of Jianchang County, Liaoning Province (Zhou, 2010b). Here we report a new species of turtle from the same locality as L. jianchangensis that represents the first soft-shelled turtle from the Jehol Biota and that provides valuable information into the early evolution of the group.

Soft-shelled turtles (Trionychidae) are an ancient, morphologically unique, and highly specialized group of aquatic cryptodires (Meylan, 1987; Ernst and Barbour, 1989; Engstrom et al., 2004; Scheyer et al., 2007; Joyce et al., 2013). Although the monophyly of this group has never been questioned, the relationship of Trionychidae to other extant cryptodiran turtles has been controversial. Trionychidae plus Carettochelyidae form the clade Trionychia (Gaffney and Meylan, 1988; Meylan, 1988; Meylan and Gaffney, 1989; Shaffer et al., 1997; Joyce et al., 2004; Joyce, 2007). Molecular studies place this clade at the base of crowngroup Cryptodira (Shaffer et al., 1997; Krenz et al., 2005;

*Corresponding author.
Parham et al., 2006; Shaffer, 2009; Barley et al., 2010; Lourenço et al., 2012), whereas unconstrained morphological studies support a more derived position nested within Cryptodira (Gaffney and Meylan, 1988; Joyce, 2007; Sterli, 2010; Anquetin, 2011; Sterli et al., 2013). The phylogenetic relationships among modern soft-shelled turtle species are still controversial, but it is generally accepted that Trionychidae consists of two clades, Cyclanorbinae and Trionychinae, and that Trionychinae includes some well-supported monophyletic clades (Meylan, 1987; Engstrom et al., 2004). The taxonomy and phylogenetic relationships of fossil trionychid species are far more controversial, and very little is known regarding the origin and early radiation of this group (Gardner et al., 1995; Joyce and Lyson, 2010, 2011; Vitek and Danilov, 2010; Vitek, 2012; Danilov and Vitek, 2013; Joyce et al., 2013). The early record of soft-shelled turtles is poor, and most taxa are based either on fragmentary shells or skulls (Yeh, 1994; Hutchison, 2000; Sukhanov, 2000; Danilov and Vitek, 2013). More complete Mesozoic skull-shell-associated materials have been described only for trionychids from the Campanian and Maastrichtian of North America (Gardner et al., 1995; Brinkman, 2005; Joyce and Lyson, 2011; Vitek, 2012) or the Cenomanian-Santonian of Mongolia (Danilov et al., 2014). The new material described herein is a nearly complete skeleton and therefore represents the first complete Early Cretaceous skullshell-associated trionychid worldwide.

\section{Age and Geological Context}

The specimen described herein was excavated from the Xiaotaizi locality, Lamadong, Jianchang County, Huludao City, Liaoning Province, China. This locality is situated about $100 \mathrm{~km}$ west of Huludao City and $135 \mathrm{~km}$ southwest of the famous Sihetun locality. The holotype comes from the Xidian bed of the first member of the Jiufotang Formation (Duan et al., 2010). The basalt from the Jiufotang Formation was dated at $110.59 \pm 0.52$ Ma in Tebch, Inner Mongolia (Eberth et al., 1993). In Liaoning, 
the lower Jiufotang Formation yielded an age of $120.3 \pm 0.7 \mathrm{Ma}$ (He et al., 2004). Recently, a tuff from the base of the Jiufotang Formation was reported an age of $122.1 \pm 0.3 \mathrm{Ma}$ (Chang et al., 2009). We therefore deduce that the fossil is approximately 120 $\mathrm{Ma}$, or Aptian in age.

\section{MATERIALS AND METHODS}

We investigated the phylogenetic placement of the new trionychid taxon by integrating it into the only well-established character/taxon matrix (Meylan, 1987), as expanded by Joyce et al. (2009) and Joyce and Lyson (2010, 2011). This matrix has since been further expanded through the modification of characters and through the addition of taxa and characters (Vitek, 2011, 2012), but we purposefully use the matrix as published by Joyce and Lyson (2011), because all characters and taxa added by Vitek $(2011,2012)$ are focused on resolving the phylogenetic relationships of North American trionychids and are therefore not relevant to the specimen at hand. To better resolve the phylogenetic placement of the new taxon, we undertook a concerted search for additional characters, including in the relevant literature (Meylan, 1987, 1988; Meylan and Gaffney, 1989; Vitek, 2011, 2012), but we were unable to find any parsimony informative characters, which further highlights the small amounts of morphological variation that are apparent within the ingroup.

The new turtle could be scored for 45 of 83 cranial and postcranial characters from all major anatomical regions. The scoring for the new taxon is 4212412311 11?04?12?2 ?1?23????? ????????? ??1??????? 1?1?12111? ?121??0000 0000002??? 000. To avoid the pitfalls associated with using a hypothetical ancestor (see Joyce and Lyson, 2010, for extensive discussion), polarity was created by using a molecular scaffold (Engstrom et al., 2004) and by assuming a monophyletic Trionychinae and Cyclanorbinae (Joyce et al., 2009; Joyce and Lyson, 2010, 2011). All characters were left unordered and unweighted, and the most parsimonious result was retrieved by running 1000 randomly seeded heuristic searches using PAUP 4.0b10 (Swofford, 2002).

\section{SYSTEMATIC PALAEONTOLOGY}

TESTUDINES Batsch, 1788

CRYPTODIRA Cope, 1868

TRIONYCHIA Hummel, 1929

PAN-TRIONYCHIDAE Joyce et al., 2004

PEROCHELYS LAMADONGENSIS, gen. et sp. nov. (Figs. 1-3)

Etymology_-'per-,' continuous (Latin), in allusion to the continuous neural series that fully separates the costals; 'chelys,' turtle (Greek); 'lamadong,' in reference to the type locality.

Holotype-IVPP (Institute of Vertebrate Paleontology and Paleoanthropology) V 18048, a nearly complete skeleton.

Locality and Horizon-Xiaotaizi locality, Lamadong, Jianchang County, Huludao City, Liaoning Province, China: $41^{\circ} 32.142^{\prime} \mathrm{N}, 121^{\circ} 01.614^{\prime} \mathrm{E}$; Jiufotang Formation; Aptian, Lower Cretaceous.

Diagnosis-Perochelys lamadongensis can be diagnosed as a representative of Pan-Trionychidae by the presence of a ' $\mathrm{V}$ 'shaped entoplastron and a 'L'-shaped epiplastra and the absence of peripheral and pygal bones. Within Pan-Trionychidae, $P$. lamadongensis differs from cyclanorbines and plastomenids by reduced development of the bridge and all plastral elements. Among pan-trionychid taxa with a reduced plastron, $P$. lamadongensis differs from all by the combined absence of a preneural, presence of a wide nuchal, lack of a midline contact of any costal (otherwise only present in Dogania subplana), and the great reduction of costal VIII (absent in Dogania subplana).

\section{DESCRIPTION}

IVPP V 18048 is a nearly complete skeleton originally exposed in dorsal view (Fig. 1). The skull and shell, however, were also prepared in ventral view. The specimen includes a partial skull in occlusion with the mandible, the cervical series, the carapace and plastron, an articulated caudal series, the pectoral and pelvic girdles, and the fore- and hind limbs. At a certain distance, the specimens appear perfectly preserved; however, the specimen is heavily crushed and the surfaces of many bones, particularly in the skull, are damaged.

\section{Skull and Mandibles}

The skull is occluded with the mandibles (Fig. 2). They are dorsoventrally crushed, and the rostrum and much of the skull roof are damaged. The skull is lentoid in dorsal view. The distance from the broken rostrum to the posterior end of the crista supraoccipitalis is $54 \mathrm{~mm}$, and the maximum width of the skull is $34 \mathrm{~mm}$ across the quadrates.

The premaxillae are not preserved. The left maxilla has lost its anterior end and dorsal process, whereas only a small ventral portion is preserved of the right one. The dorsal border of the posterior process of the maxilla forms the ventral margin of the orbit and posteriorly underlaps the jugal. Small nutrient foramina are distributed on the mid-ventral part of the maxilla in lateral view.

The orbit is oval and large, with a diameter about four times the width of postorbital bar (Fig. 2A). The orbit margin is formed by the maxilla ventrally, the frontal dorsally, and the postorbital and the jugal posteriorly. The interorbital bar is wider than the postorbital bar.

The prefrontals are not preserved except perhaps for the posterior tip on the left side (Fig. 2A). The left frontal is preserved, whereas the right one is missing. The frontal is a nearly triangular bone in dorsal view and forms most of the dorsal margin of the orbit. It has a narrow anterior margin contacting the prefrontal and a jagged posterior margin contacting the parietal posteriorly and the postorbital posterolaterally. The postorbital is a small element between the parietal and the jugal. It is isolated from the temporal emargination as in most trionychids (Meylan, 1987). The paired parietals are quite long, extending posteriorly to approximately the level of the occipital condyle. The crista supraoccipitalis extends posteriorly, reaching the middle point of the second cervical.

The temporal emargination is elongate and very deep and the processus trochlearis oticum is exposed dorsally (Fig. 2A). The processus trochlearis oticum is trough-like, and dorsally concave. It is formed at least by the quadrate and the prootic; whether the parietal contributes to this processus is uncertain, but its contribution cannot have been large. The prootic is roughly trapeziform and forms the major part of the processus trochlearis oticum. The large foramen stapedio-temporalis lies between the prootic and the quadrate but mainly in the former.

The jugal bifurcates into vertical and horizontal rami, but the base of the vertical ramus is lost. The vertical ramus extends dorsally to contact the parietal, forming the major part of the postorbital bar; the thin, low horizontal ramus extends posteriorly to contact the squamosal and the region of the quadratojugal, forming almost all the temporal arch. The jugal forms the anterior limit of the cheek emargination, whose ventral margin is in line with the lower rim of the orbit. The quadratojugal cannot be identified due to the poor preservation of the portion between the jugal and quadrate. 

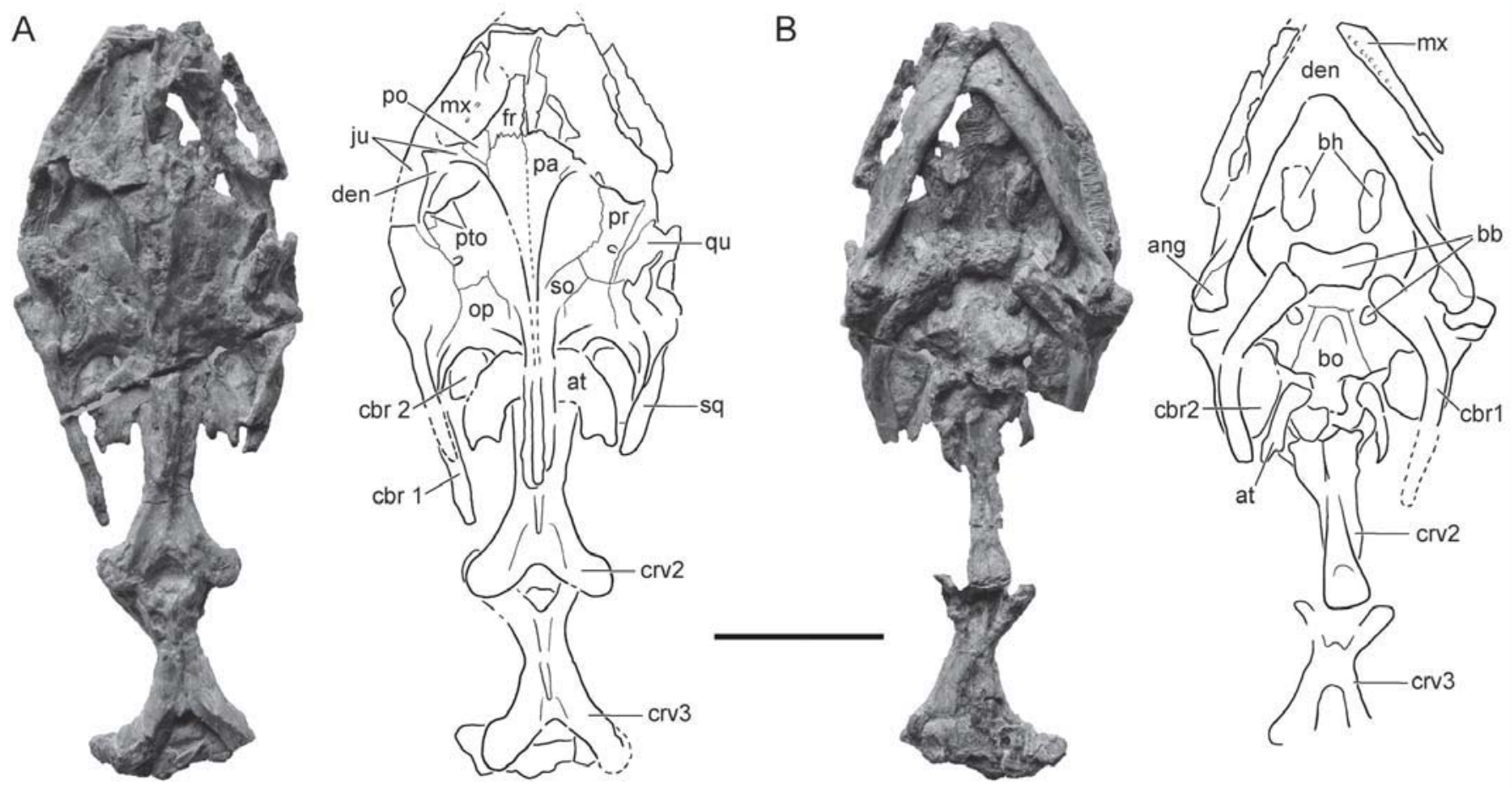

FIGURE 2. IVPP V 18048, holotype, Perochelys lamadongensis, gen. et sp. nov., Early Cretaceous, Jiufotang Formation, Liaoning Province, China. $\mathbf{A}$, skull and mandible in dorsal view; $\mathbf{B}$, skull and mandible in ventral view. Hatching indicates the processus trochlearis oticum. Abbreviations: ang, angular; at, atlas; bb, basibranchial; bh, basihyal; bo, basioccipital; cbr, cornu branchiale; crv, cervical vertebrae; den, dentary; fr, frontal; ju, jugal; mx, maxilla; op, opisthotic; pa, parietal; po, postorbital; pr, prootic; pto, processus trochlearis oticum; qu, quadrate; so, supraoccipital; sq, squamosal. Scale bar equals $20 \mathrm{~mm}$.

The squamosal is quite long, forming the lateral wall of the temporal emargination. Its narrow anterior process is crushed ventrally, contacting the jugal and perhaps the quadratojugal. The squamosal is broadly articulated with the quadrate ventrally and medially, the opisthotic posteromedially. Its posterior crest is rather low and reaches almost as far posteriorly as the crista supraoccipitalis.

The palate is poorly preserved and provides little information (Fig. 2B). In the occiput, a foramen on the left side of the occipital condyle is identified as the foramen jugulare posterius. The posterior basicranial region is either crushed or covered by hyoid bones, but it appears that the foramen jugulare posterius is separated from the fenestra postotica, although it is unclear which bone or bones form this separation.

Both mandibular rami are preserved, although the anterior tip of the left one is missing (Fig. 2B). The two rami form an angle of about $50^{\circ}$. The processus coronoideus is prominently developed and has its greatest height in the middle of the lower jaw. The articularis mandibularis area is not well developed.

\section{Hyoid Apparatus}

Nine ossifications are recognized as elements of the hyoid apparatus (Fig. 2B). Their pattern is similar to that of the extant species Aspideretes hurum (Meylan, 1987). Five of them (or three pairs) form the corpus hyoidis. The distantly placed basihyals are anteroposteriorly longer than the anterior pair of basibranchials, and the posterior basibranchials are split and dislocated in ventral view laterally under the cornu branchiale I. The cornu branchiale I is bracket-shaped and longer than $30 \mathrm{~mm}$. The cornu branchiale II likely consists of a single, narrow element.

\section{Vertebrae and Ribs}

At least five cervicals, 10 thoracics, two sacrals, and 17 caudals are present (Figs. 2, 3). Cervicals I through III are articulated with the skull and exposed in dorsal and ventral views. The remaining cervicals are covered by sediment. The atlas intercentrum was broken and split into two fragments that frame the basioccipital process. The centrum of the axis is slightly shifted to the right from the original position, whereas the atlas neural arches remain in situ. Cervicals II and III are quite long, opisthocoelous, and with a length four times their width. The ventral keel is thin and weak on the anterior half of the second centrum, unclear on the third. The neural spine is low and thin, and its height decreases towards the posterior on cervicals II and III. Thoracics I through III are covered, whereas thoracics IV through $\mathrm{X}$ are exposed in ventral view. The thoracic centra are articulated with the ribs and with their neighbors. Two sacrals are exposed in both dorsal and ventral views. The first sacral rib is wider along its distal end than the second. The caudal centra decrease in size posteriorly, whereas the transverse processes decrease in width posteriorly.

\section{Carapace and Plastron}

The carapace is small, with a length of $123 \mathrm{~mm}$ and a maximum width of $136 \mathrm{~mm}$ (Figs. 1, 3A). It is subcircular, with a small notch at the posterior border as in the extant trionychid Dogania subplana. All costals and neurals are fully sculptured on the dorsal surface, but the nuchal only shows a hint of a callosity near its posteromedial margin. The nuchal is bow-shaped and wide, with a width about five times its length, and the costiform processes are united. The nuchal does not have any sutural contacts with the remaining carapace. The suprascapular fontanelles are open and confluent. The neural series includes eight continuous 

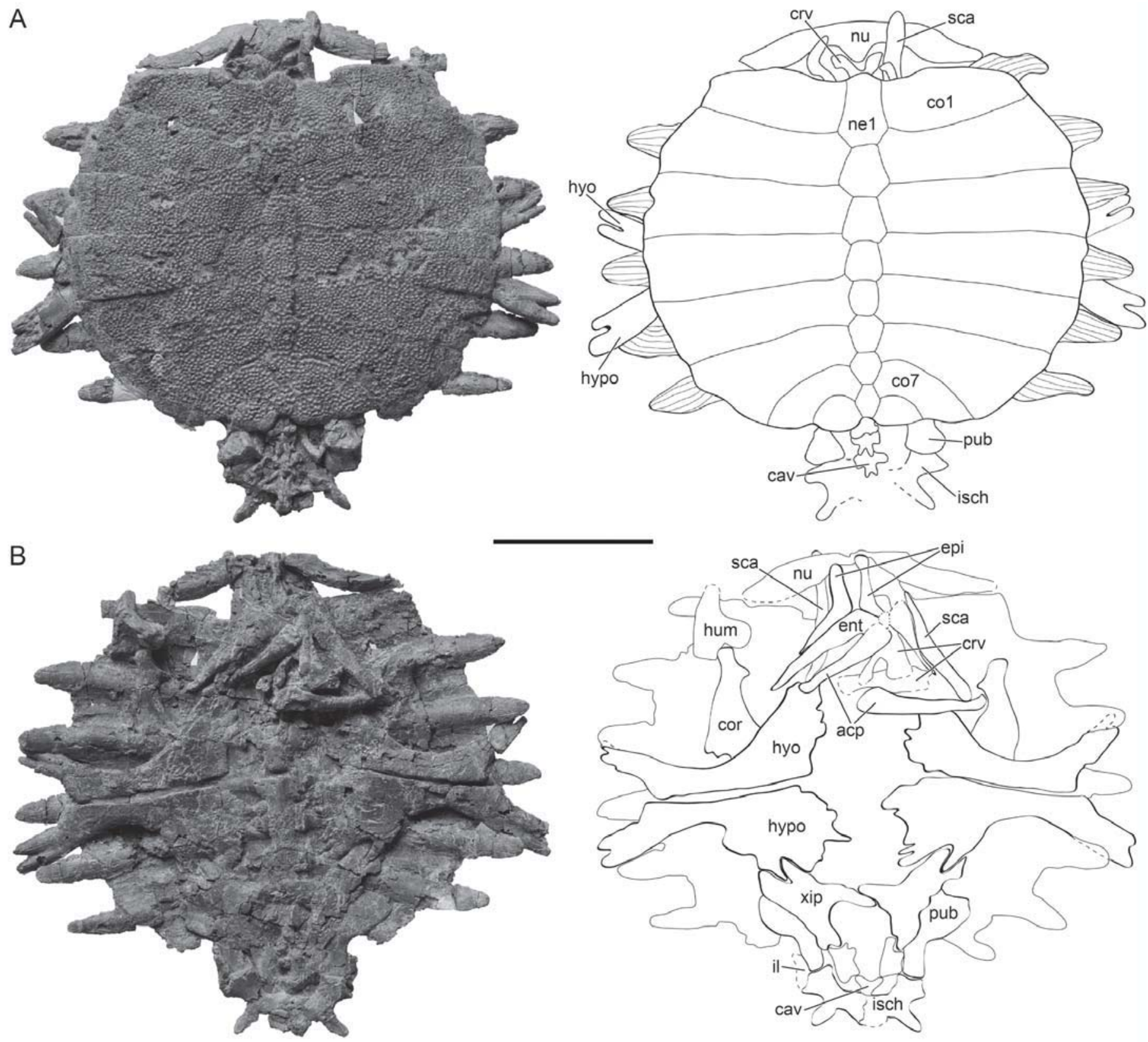

FIGURE 3. IVPP V 18048, holotype, Perochelys lamadongensis, gen. et sp. nov., Early Cretaceous, Jiufotang Formation, Liaoning Province, China. A, carapace and plastron in dorsal view; B, carapace and plastron in ventral view. Abbreviations: acp, acromion process; cav, caudal vertebrae; crv, cervical vertebrae; co, costal bone; cor, coracoid; ent, entoplastron; epi, epiplastron; hum, humerus; hyo, hyoplastron; hypo, hypoplastron; il, ilium; isch, ischium; ne, neural bone; nu, nuchal bone; pub, pubis; sca, scapula; xip, xiphiplastron. Scale bar equals $50 \mathrm{~mm}$.

neurals and lacks a preneural. Neural I is heptagonal and contacts two pairs of costals laterally. Neural $\mathrm{V}$ is tetragonal and only contacts (i.e., costal Vs) laterally. The remaining neurals are nearly hexagonal and contact two pairs of costals laterally. The anterior and posterior pairs of costal contacts are of unequal length: the shorter costal contact faces posteriorly in neurals I to IV and VIII, anteriorly in neurals VI and VII. The reversal of the orientation therefore occurs at neural V. There are eight pairs of costals, where costals III and IV are mediolaterally longer than all other costals. Costal VI is expanded along its lateral border. Costal VIIIs do not meet along the midline and extend more posteriorly than neural VIII. The eighth costals are extremely short. Peripherals are absent.
The plastron consists of nine elements, and these elements do not form a solid plate (Fig. 3B). The general shape and interrelationships of the nine bones are very similar to those of Pelodiscus sinensis. Weak sculpturing is only present on the middle part of the hyoplastra, hypoplastra, and xiphiplastra. Although the callosities are poorly developed on the hyoplastra, hypoplastra, and xiphiplastra, we nevertheless score them as being present. The epiplastra are 'J'-shaped, with an anterior extension of intermediate length. The entoplastron is boomerang-shaped, but the angle between the two rami is unclear, because the entoplastron is broken along the midline and the elements appear shifted. The hyoplastra are sutured but not fused with the hypoplastra. The hyoplastra and 
hypoplastra do not meet their counterparts at the midline. The bridge is short, less than one-fifth of the hypoplastron width. The hyoplastron has at least three medially directed processes, and its lateral lobe is shorter than the medial lobe. The medial margin of the hypoplastron is poorly preserved, but the medial hypoplastral processes seem clustered rather than divided. The xiphiplastra meet along the midline via their anterior and posterior medial processes; between them lies a relatively large fenestra. The anterior xiphiplastral processes are positioned on either side of the most lateral of the posterior hypoplastral processes.

\section{Girdles and Appendages}

Both the pectoral and pelvic girdles are preserved (Fig. 3B). Their shape is essentially the same as that of Pelodiscus sinensis. The triradiate pectoral girdle is broken, and the coracoid is dislocated from the scapula. The coracoid is well exposed except for its distal end, which is hidden by the plastron. Its articular facet for the scapula is concave. The dorsal end of the main body of the scapula is exposed dorsal to the nuchal. This dorsal projection is rather long, longer than the acromion process. The ilium was lost during preparation, but it was observed that the dorsal process is curved posteriorly. The pubes are partially covered by the plastron ventrally. The anterolaterally extended pectineal process is wide, at least as wide as the length of interpubic contact. The two pectineal processes lie in a single plane with the interpubic symphysis, and they broadly contact the xiphiplastron. The thyroid fenestra is a large, confluent opening between the pubes and ischia, and the ischium does not send a process into the thyroid fenestra. The ischium produces a distinct posterolateral directed process, the metischial process.

Nearly all appendicular elements are preserved, but the phalanges of the hand are partially disarticulated, and it is therefore not possible to deduce the manual formula (Fig. 1). The ectepicondylar foramen is open. The elements of the hind limb are longer and more robust than the corresponding elements of the forelimb. Three small phalanges that are much smaller than most other phalanges remain articulated on the left hand. Given that the smallest element of this series is an distal phalanx that lacks a claw, that all elements are shorter than most other phalanges, and that Perochelys lamadongensis likely had three claws on its first three digits, we conclude that digit IV or V had a series of at least four phalanges (Delfino et al., 2010). The observed phalangeal formula of the pes is 1-3-3-4-1 and the last phalanx of digits II and III is claw-shaped, but there should be a claw on the first digit and the formula should be 2-3-3-4 for digits I-IV.

\section{COMPARISON AND DISCUSSION}

\section{Alpha Taxonomic Considerations}

In comparison with recent trionychids, Perochelys lamadongensis is similar to Dogania subplana, Pelodiscus sinensis, and Apalone mutica in its shell morphology. In particular, these taxa have a nuchal that has a width greater than four times its length and lack a preneural. Among recent trionychines, only members of Aspideretes have preneurals, but this character is rather common among fossils (Hay, 1908; Joyce et al., 2009). None of the costals meet along the midline in P. lamadongensis. Among recent trionychids, this condition is recognized only in Dogania subplana and unambiguously interpreted as a highly derived autapomorphy (Meylan, 1987; Engstrom et al., 2004). The costal VIIIs of P. lamadongensis are reduced, as in Apalone spp. and Rafetus spp. Perochelys lamadongensis resembles Pelodiscus sinensis in cranial morphology: the jugal contacts the squamosal posteriorly and the parietal dorsally, the foramen jugulare posterius is separated from the fenestra postotica, the postorbital bar is moderate relative to the orbit, and the processus trochlearis oticum is mainly formed by the prootic, with less than a third being contributed from the quadrate (Meylan, 1987).

Among fossil taxa, the Late Cretaceous 'Aspideretes' maortuensis has been reported to have a complete neural series (Yeh, 1965; Karl, 1999) and may therefore resemble Perochelys lamadongensis in this regard (Table 1). However, examination of the holotype of 'Aspideretes' maortuensis clearly reveals that this taxon has a short, diamond-shaped neural VIII that does not contribute to the carapacial rim. Both taxa nevertheless resemble one another greatly in the poor development of plastral callosities. Perochelys lamadongensis resembles the Late Cretaceous Apalone latus in having a reversal at neural $\mathrm{V}$ and reduced costal VIIIs. However, the lateral margin of costal V is more expanded than that of costal VI and costal VIIIs meet at the midline in the latter (Gardner et al., 1995). Perochelys lamadongensis is different from Aspideretoides spp. from the Late Cretaceous and Paleogene in lacking a preneural and in lacking a postorbital contribution to the upper temporal emargination (Gardner et al., 1995). The Late Cretaceous 'Trionyx' kansaiensis is larger and possesses a strong nuchal emargination (Vitek and Danilov, 2010). The new species is similar to the Late Cretaceous 'Trionyx' kyrgyzensis in having poorly developed plastral callosities, but differs in having an anteroposteriorly shorter nuchal and shorter xiphiplastra (Nessov, 1995). Perochelys lamadongensis is different from the Late Cretaceous Axestemys spp. by its small size, by lack of a preneural, and in the type of sculpturing (Vitek, 2012). The comparisons between P. lamadongensis and other Cretaceous trionychids are summarized in Table 1. The cumulative differences fully justify recognizing it as a new species of fossil pan-trionychid.

\section{Phylogenetic Considerations}

Our phylogenetic analysis reveals that 10 most parsimonious solutions can be retrieved with 264 steps that differ only in the placement of Perochelys lamadongensis (Fig. 4). The new fossil turtle is placed equally well as sister to the extant trionychids Nilssonia formosa, Dogania subplana, or Pelodiscus sinensis, or as sister to the clades Apalonina or Gigantaestuarochelys (sensu Engstrom et al., 2004), or along the stem of Trionychinae, Cyclanorbinae, or even Trionychidae. The only portion of the tree from which P. lamadongensis is notably absent is Cyclanorbinae and Plastomenidae. This poor result is surprising, given that $P$. lamadongensis is known from a complete skeleton and could be scored for more than half $(54 \%)$ of characters. High levels of homoplasy have long been known to make it difficult to retrieve solid phylogenetic result within Trionychidae (Meylan, 1987) and high levels of homoplasy (consistency index $[\mathrm{CI}]=0.31$ ) are clearly to blame here as well. The observation that $P$. lamadongensis can be placed equally well within the tips of the tree as well as at the base is nevertheless revealing, because it demonstrates that it is currently still not possible to even partially unravel the morphological evolution at the base of Trionychidae. The possible placement of $P$. lamadongensis as sister to crown Trionychidae forces us to conservatively classify the new fossil as a representative of the total group of crown Trionychidae (Pan-Trionychidae sensu Joyce et al., 2004) and hints at the possibility that the poorly ossified trionychine morphotype seen in P. lamadongensis may be the basal condition for Trionychidae (see Joyce and Lyson, 2010). The frustrating lack of character that would allow us to resolve the basal evolution of crown Trionychidae, by contrast, supports the notion that soft-shelled turtles quite rapidly acquired the substantial list of characteristic traits that distinguish them so clearly from all other turtles (Meylan, 1987), likely during the Early Cretaceous, but did not change significantly over the course of their Late Cretaceous to Recent evolution, at least as currently preserved.

The uncertainty regarding the phylogenetic placement of $P$. lamadongensis is highly unfortunate, because this taxon cannot 
TABLE 1. Comparison of shell characters of some species of Cretaceous pan-trionychines.

\begin{tabular}{|c|c|c|c|c|c|c|c|}
\hline Dimension & $\begin{array}{l}\text { Aspideretoides } \\
\text { foveatus }\end{array}$ & $\begin{array}{l}\text { Aspideretoides } \\
\text { riabinini }\end{array}$ & $\begin{array}{l}\text { Axestemys } \\
\text { splendida }\end{array}$ & $\begin{array}{l}\text { 'Trionyx' } \\
\text { kansaiensis }\end{array}$ & $\begin{array}{l}\text { 'Trionyx' } \\
\text { kyrgyzensis }\end{array}$ & $\begin{array}{l}\text { 'Aspideretes' } \\
\text { maortuensis }\end{array}$ & $\begin{array}{c}\text { Perochelys } \\
\text { lamadongensis }\end{array}$ \\
\hline Nuchal emargination & Absent & Weak & Weak & Strong & Absent & $?$ & Absent \\
\hline $\begin{array}{l}\text { Times of nuchal width } \\
\text { to length }\end{array}$ & 6 & $4-6$ & 5 & $5-6$ & 5 & ? & 5 \\
\hline Preneural & Present & Present & Present & Absent & $?$ & Absent & Absent \\
\hline Number of neurals & 7 & 7 & 7 & 8 & 8 & 8 & 8 \\
\hline Neural reversal & 5 or adjacent & 5 or 6 & 5 & 5 & 5 & 6 & 5 \\
\hline $\begin{array}{l}\text { Neural series separates } \\
\text { completely costals }\end{array}$ & No & No & No & No & No & $?$ & Yes \\
\hline Costal VIIIs reduced & Yes & Yes & Yes & No & No & Yes & Yes \\
\hline Plastral sculpturing & Developed & Developed & Developed & Developed & Poorly developed & Medial & Poor developed \\
\hline $\begin{array}{l}\text { Lateral hyoplastron lobe } \\
\text { in relation to medial } \\
\text { hyoplastron lobe }\end{array}$ & Shorter & Shorter & Shorter & Longer & Longer & Shorter & Shorter \\
\hline $\begin{array}{l}\text { Ratio of minimal bridge } \\
\text { length to maximal } \\
\text { hypoplastral length }\end{array}$ & About $50 \%$ & About $50 \%$ & About $50 \%$ & $50-60 \%$ & About $50 \%$ & About $50 \%$ & About $30 \%$ \\
\hline $\begin{array}{l}\text { Medial hypoplastral } \\
\text { processes }\end{array}$ & Divided & Divided & Divided & Clustered & Clustered & Clustered & Clustered \\
\hline
\end{tabular}

help inform the debate regarding the age of the trionychid crown. A recent molecular divergence dating analysis using highly conservative, fossil-based priors calculated the divergence of Trionychidae to range from 86 (Coniacian) to 126 (Aptian)

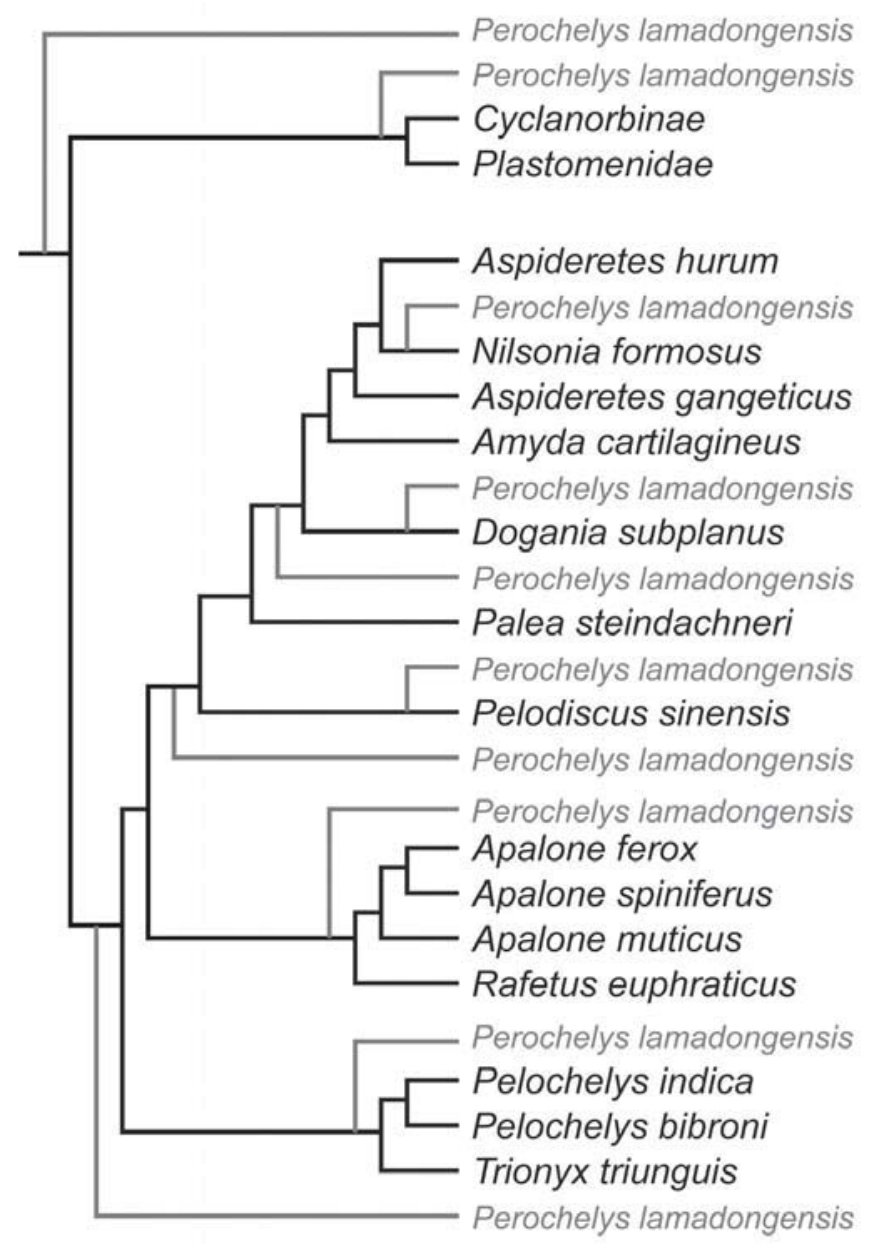

FIGURE 4. Ten equally parsimonious placements of Perochelys lamadongensis, gen. et sp. nov. (indicated in gray), within a topology imposed by a molecular scaffold. The new taxon is found throughout the tree but is notably absent only from Cyclanorbinae and Plastomenidae.
Ma, with a mean at 105 Ma (Albian) (Joyce et al., 2013). These dates are broadly consistent with the conclusion that the Aptian $P$. lamadongensis might be a stem or crown trionychid. However, unless extremely high rates of morphological evolution are proposed at the base of the trionychine stem lineage, the great age of $P$. lamadongensis makes it more likely that the trionychine morphotype indeed represents the basal morphology of the trionychid crown group.

\section{Temporal Considerations}

Sinaspideretes wimani was thought to be the oldest known member of Trionychidae (Young and Chow, 1953), but this view is no longer tenable (Meylan and Gaffney, 1992) and the material is now thought to represent an adocusian (Tong et al., 2014). The oldest diagnosable pan-trionychid material was therefore thought to be 'Aspideretes' maortuensis and 'A'. alashanensis from Maortu, Jilantai, Alxa (Albian or Aptian), and 'Trionyx' kyrgyzensis from the upper part of the Alamyshik Formation of Kyrgyzstan (lower-middle Albian) (Yeh, 1965; Nessov, 1995). The Maortu turtles have since been shown to be Late Cretaceous in age (Brinkman et al., 2008). Fragmentary shell remains have recently been described from the Hauterivian to Albian of Japan under the name Kappachelys okurai that show the incipient shell microstructure of extant trionychids and therefore represent the basal stem lineage of the group (Hirayama, 2005; Nakajima et al., 2009; Hirayama et al., 2013). Although the results of our analysis are disappointing in that the phylogenetic placement of Perochelys lamadongensis is unclear, it is nevertheless apparent that this taxon is among the first turtles with modern trionychid characteristics.

\section{ACKNOWLEDGMENTS}

We thank X.-L. Wang and Z.-H. Zhou (Institute of Vertebrate Paleontology and Paleoanthropology) for help during the collection the specimen, R. Hirayama (Teikyo Heisei University), D. Brinkman (Royal Tyrrell Museum of Palaeontology), and C.-F. Zhou (Shenyang Normal University) for references. D. Brinkman, I. Danilov, P. Meylan, H. Tong, and N. Vitek are thanked for numerous comments that significantly helped improve the quality of the manuscript. Funding for this work was provided by National Natural Science Foundation of China Grant 41172017 and National Basic Research Program of China (973 Program) Grant 2012CB821902. 


\section{LITERATURE CITED}

Anquetin, J. 2011. Evolution and palaeoecology of early turtles: a review based on recent discoveries in the Middle Jurassic. Bulletin de la Société Géologique de France 182:231-240.

Barley, A. J., P. Q. Spinks, R. C. Thomson, and H. B. Shaffer. 2010. Fourteen nuclear genes provide phylogenetic resolution for difficult nodes in the turtle tree of life. Molecular Phylogenetics and Evolution 55:1189-1194.

Batsch, A. J. G. C. 1788. Versuch einer Anleitung, zur Kenntniß und Geschichte der Thiere und Mineralien. Akademische Buchhandlung, Jena, 528 pp.

Brinkman, D. B. 2005. Turtles: diversity, paleoecology, and distribution; pp. 202-220 in P. J. Currie and E. B. Koppelhus (eds.), Dinosaur Provincial Park: A Spectacular Ancient Ecosystem Revealed. Indiana University Press, Bloomington, Indiana.

Brinkman, D. B., J. Li, and X. Ye. 2008. Order Testudines; pp. 35-103 in J. Li, X. Wu, and F. Zhang (eds.), The Chinese Fossil Reptiles and Their Kin. Science Press, Beijing.

Chang, M.-M., P.-J. Chen, Y.-Q. Wang, and Y. Wang. 2003. The Jehol Biota: The Emergence of Feathered Dinosaurs, Beaked Birds and Flowering Plants. Shanghai Scientific and Technical Publishers, Shanghai, $208 \mathrm{pp}$.

Chang, S.-C., H. Zhang, P. R. Renne, and Y. Fang. 2009. High-precision ${ }^{40} \mathrm{Ar} /{ }^{39} \mathrm{Ar}$ age for the Jehol Biota. Palaeogeography, Palaeoclimatology, Palaeoecology 280:94-104.

Cope, E. D. 1868. On the origin of genera. Proceedings of the Academy of Natural Sciences of Philadelphia 20:242-300.

Danilov, I. G., and N. S. Vitek. 2013. Cretaceous trionychids of Asia: an expanded review of their record and biogeography; pp. 419-438 in D. B. Brinkman, P. A. Holroyd, and J. D. Garnder (eds.), Morphology and Evolution of Turtles. Springer, Dordrecht.

Danilov, I. G., Hirayama, R., Sukhanov, V. B., Suzuki, S., Watabe, M., and N. S. Vitek. 2014. Cretaceous soft-shelled turtles (Trionychidae) of Mongolia: new diversity, records, and a revision. Journal of Systematic Palaeontology. 12:799-832.

Delfino, M., U. Fritz, and M. R. Sáchez-Villagra. 2010. Evolutionary and developmental aspects of phalangeal formula variation in pig-nose and soft-shelled turtles (Carettochelyidae and Trionychidae). Organisms Diversity and Evolution 10:69-79.

Duan, Y., L. Zhang, L. Zhang, and D. Hu. 2010. [Division and correlation of precious fossil-bearing beds of the Jiufotang Formation in Jianchang Basin western Liaoning, China. Chinese Journal of Geology 45:606-613. [Chinese]

Eberth, D. A., D. D. Russell, D. R. Braman, and A. L. Deino. 1993. The age of the dinosaur-bearing sediments at Tebch, Inner Mongolia, People's Republic of China. Canadian Journal of Earth Sciences 30:2101-2106.

Endo, R., and T. Shikama. 1942. Mesozoic reptilian fauna in the Jehol mountainland, Manchoukuo. Bulletin of the Central National Museum of Manchoukuo 3:1-20. [Japanese]

Engstrom, T. N., H. B. Shaffer, and W. P. McCord. 2004. Multiple data sets, high homoplasy, and the phylogeny of softshell turtles (Testudines: Trionychidae). Systematic Biology 53:693-710.

Ernst, C. H., and R. W. Barbour. 1989. Turtles of the World. Smithsonian Institution Press, Washington, D.C., 290 pp.

Gaffney, E. S., and P. A. Meylan. 1988. A phylogeny of turtles; pp. 157-219 in M. J. Benton (ed.), The Phylogeny and Classification of the Tetrapods. Claredon Press, Oxford, U.K.

Gardner, J. D., A. P. Russell, and D. B. Brinkman. 1995. Systematics and taxonomy of soft-shelled turtles (Family Trionychidae) from the Judith River Group (mid-Campanian) of North America. Canadian Journal of Earth Sciences 32:631-643.

Goloboff, P. A., J. S. Farris, and K. C. Nixon. 2008. TNT, a free program for phylogenetic analysis. Cladistics 24:774-786.

He, H.-Y., X.-L. Wang, Z.-H. Zhou, F. Wang, A. Boven, G.-H. Shi, and R.-X. Zhu. 2004. Timing of the Jiufotang Formation (Jehol Group) in Liaoning, northeastern China, and its implications. Geophysical Research Letters 31:1-4.

Hirayama, R. 2005. New materials of non-marine turtles from the Early Cretaceous Tetori Group of former Shiramine-mura of Hakusan City, Ishikawa Prefecture, Central Japan; pp. 12-20 in Shiramine Village Board of Education (ed.), Scientific Report on Fossil Animals of Kuwajima "Kaseki-kabe" (Fossil-bluff) from the Kuwajima Formation, Tetori Group, Hakusan,
Ishikawa, Japan. Shiramine Village Board of Education, Ishikawa Prefecture, Japan. [Japanese]

Hirayama, R., S. Isaji, and T. Hibino. 2013. Kappachelys okurai gen. et sp. nov., a new stem soft-shelled turtle from the Early Cretaceous of Japan; pp. 176-186 in D. B. Brinkman, P. A. Holroyd, and J. D. Garnder (eds.), Morphology and Evolution of Turtles. Springer, Dordrecht.

Hutchison, J. H. 2000. Diversity of Cretaceous turtle faunas of eastern Asia and their contribution to the turtle faunas of North America. Paleontological Society of Korea Speical Publication 4:27-38.

Hummel, K. 1929. Die fossilen Weichschildkröten (Trionychia). Geologische und Palaeontologische Abhandlungen 16:359-487.

Ji, S.-A. 1995. Part 3. Reptiles; pp. 140-146 in D. Ren, L.-W. Lu, Z.-G. Guo, and S.-A. Ji (eds.), Faunae and Stratigraphy of Jurassic-Cretaceous in Beijing and the Adjacent Areas. Seismological Press, Beijing. [Chinese]

Joyce, W. G. 2007. Phylogenetic relationships of Mesozoic turtles. Bulletin of the Peabody Museum of Natural History 48:3-102.

Joyce, W. G., and T. R. Lyson. 2010. A neglected lineage of North American turtles fills a major gap in the fossil record. Palaeontology 53:241-248.

Joyce, W. G., and T. R. Lyson. 2011. New material of Gilmoremys lancensis nov. comb. (Testudines: Trionychidae) from the Hell Creek Formation and the diagnosis of plastomenid turtles. Journal of Paleontology 85:444-461.

Joyce, W. G., J. F. Parham, and J. A. Gauthier. 2004. Developing a protocol for the conversion of rank-based taxon names to phylogenetically defined clade names, as exemplified by turtles. Journal of Paleontology 78:989-1013.

Joyce, W. G., A. Revan, T. R. Lyson, and I. G. Danilov. 2009. Two new plastomenine softshell turtles from the Paleocene of Montana and Wyoming Bulletin of the Peabody Museum of Natural History 50:307-325.

Joyce, W. G., J. F. Parham, T. R. Lyson, R. C. M. Warnock, and P. C. J. Donoghue. 2013. A divergence dating analysis of turtles using fossil calibrations: an example of best practices. Journal of Paleontology 87:612-634.

Karl, H.-V. 1999. Paleogeography and systematics of the genus Dogania Gray, 1844 (Testudines: Trionychidae). Studia Geologica Salmanticensia 35:3-8.

Krenz, J. G., G. J. P. Naylor, H. B. Shaffer, and F. J. Janzen. 2005. Molecular phylogenetics and evolution of turtles. Molecular Phylogenetics and Evolution 37:178-191.

Li, J.-L., and J. Liu. 1999. The skull of Manchurochelys liaoxiensis (Testudines: Sinemydidae) from the Yixian Formation of Beipiao, Liaoning and phylogenetic position of this taxon. Palaeoworld 11 Jehol Biota:281-293.

Lourenço, J. M., J. Claude, N. Galtier, and Y. Chiari. 2012. Dating cryptodiran nodes: origin and diversification of the turtle superfamily Testudinoidea. Molecular Phylogenetics and Evolution 62:496-507.

Meylan, P. A. 1987. The phylogenetic relationships of soft-shelled turtles (Family Trionychidae). Bulletin of the American Museum of Natural History 186:4-101.

Meylan, P. A. 1988. Peltochelys dollo and the relationships among the genera of the Carettochelyidae (Testudines: Reptilia). Herpetologica $44: 440-450$

Meylan, P. A., and E. S. Gaffney. 1989. The skeletal morphology of the Cretaceous cryptodiran turtle, Aducus, and the relationships of the Trionychoidea. American Museum Novitates 2941:1-60.

Meylan, P. A., and E. D. Gaffney. 1992. Sinaspideretes is not the oldest trionychid turtle. Journal of Vertebrate Paleontology 12:257-259.

Nakajima, Y., I. G. Danilov, and R. Hirayama. 2009. Plywood-like structures in costal bones of Mid- to Late Cretaceous trionychids from Asia. Gaffney Turtle Symposium, Drumheller, Alberta, October 1718, 2009. Special Publication of the Royal Tyrrell Museum, Drumheller, Alberta:128A.

Nessov, L. A. 1995. On some Mesozoic turtles of the Fergana depression (Kyrgyzstan) and Dzhungar Alatau ridge (Kazakhstan). Russian Journal of Herpetology 2:134-141.

Parham, J. F., C. R. Feldman, and J. L. Boore. 2006. The complete mitochondrial genome of the enigmatic bigheaded turtle (Platysternon): description of unusual genomic features and the reconciliation of phylogenetic hypotheses based on mitochondrial and nuclear DNA. BMC Evolutionary Biology 6:11.

Scheyer, T. M., P. M. Sander, W. G. Joyce, W. Böhme, and U. Witzel. 2007. A plywood structure in the shell of fossil and living soft- 
shelled turtles (Trionychidae) and its evolutionary implications. Organisms Diversity and Evolution 7:135-144.

Shaffer, H. B. 2009. Turtles (Testudines); pp. 398-401 in S. B. Hedges and S. Kumar (eds.), The Timetree of Life. Oxford University Press, Oxford, U.K.

Shaffer, H. B., P. A. Meylan, and M. L. McKnight. 1997. Tests of turtle phylogeny: molecular, morphological, and paleontological approaches. Systematic Biology 46:235-268.

Sterli, J. 2010. Phylogenetic relationships among extinct and extant turtles: the position of Pleurodira and the effects of the fossils on rooting crown-group turtles. Contributions to Zoology 79:93-106.

Sterli, J., D. Pol, and Laurin L. 2013. Incorporating phylogenetic uncertainty on phylogeny-based palaeontological dating and the timing of turtle diversification. Cladistics 29:233-246.

Sukhanov, V. B. 2000. Mesozoic turtles of Middle and Central Asia; pp 309-367 in M. J. Benton, M. A. Shishkin, D. M. Unwin and E. N. Kurochkin (eds.), The Age of Dinosaurs in Russia and Mongolia. Cambridge University Press, Cambridge, U.K.

Swofford, D. L. 2002. PAUP: Phylogenetic Analysis Using Parsimony (*And Other Methods). Sinauer Associates, Sunderland, Massachusetts.

Tong, H., S.-A. Ji, and Q. Ji. 2004. Ordosemys (Testudines: Cryptodira) from the Yixian Formation of Liaoning Province, northeastern China: new specimens and systematic revision. American Museum Novitates 3438:1-22.

Tong, H., L. Li, and H. Ouyang. 2014. A revision of Sinaspideretes wimani Young \& Chow, 1953 (Testudines: Cryptodira: Trionychoidae) from the Jurassic of the Sichuan Basin, China. Geological Magazine 151:600-610.

Vitek, N. S. 2011. Insights into the taxonomy and systematics of North American Eocene soft-shelled turtles from a well-preserved specimen. Bulletin of the Peabody Museum of Natural History 52:189-208.
Vitek, N. S. 2012. Giant fossil soft-shelled turtles of North America. Palaeontologia Electronica 15:43. Available at http://palaeoelectronica.org/content/2012-issue-1-articles/210-giant-soft-shelledturtles

Vitek, N. S., and I. G. Danilov. 2010. New materical and a reassessment of soft-shelled turtles (Trionychidae) from the Late Cretaceous of Middle Asia and Kazakhstan. Journal of Vertebrate Paleontology 30:383-393.

Yeh, H.-K. 1965. New material of fossil turtles of Inner Mongolia. Vertebrata PalAsiatics 9:47-69. [Chinese]

Yeh, H.-Ku. 1994. Fossil and Recent Turtles of China. Science Press, Beijing, $112 \mathrm{pp}$

Young, C.-C., and M.-M. Chow. 1953. New Mesozic reptiles from Szechuan. Acta Scientica Sinica 2:216-243. [Chinese]

Zhou, C.-F. 2010a. A second specimen of Manchurochelys manchoukuoensis Endo and Shikama, 1942 (Testudines: Eucryptodira) from the Early Cretaceous Yixian Formation of western Liaoning, China. Zootaxa 2534:57-66.

Zhou, C.-F. 2010b. A new eucryptodiran turtle from the Early Cretaceous Jiufotang Formation of western Liaoning, China. Zootaxa 2676:45-56.

Zhou, Z.-H., P. M. Barrett, and J. Hilton. 2003. An exceptionally preserved Lower Cretaceous ecosystem. Nature 421:807-814.

Submitted January 15, 2014; revisions received March 17, 2014; accepted March 24, 2014.

Handling editor: Juliana Sterli.

Citation for this article: Li, L. W. G. Joyce, and J. Liu. 2015. The first soft-shelled turtle from the Jehol Biota of China. Journal of Vertebrate Paleontology. DOI: 10.1080/02724634.2014.909450. 